\title{
Problem-solution Structures in Persuasive Texts: Effects on Attention, Comprehensiom, and Yielding
}

\begin{abstract}
This study addresses the question of how problem-solution structures influence the processing of persuasive texts. In Experiment 1, 48 students read ads containing problem, solution, and company information on a computer. The position of the company information was varied: It came either before the problem and solution, between these two parts, or after them. Ads starting with problem information received more attention than ads starting with company information. The company information received less attention only when it came last. In Experiment 2, 216 students read one ad. They recognized the company information better when it was positioned first. Furthermore, they were less persuaded when the ad contained problem-solution information compared to an ad containing only company information. The problem-solution structure can capture the readers' attention for uninteresting information but at the cost of reducing its recognition and persuasiveness.
\end{abstract}

Much effort is devoted to studying the question of which text characteristics make readers yield to a text's claims. That readers have to pay attention to the text first, is usually taken for granted. However, as the number of persuasive texts heavily outnumbers the number of texts being read, the question of why some texts succeed in capturing the readers' attention whereas others fail to do so, is an important one. Still, little is known about what makes people read a tẹt (cf. Chaiken \& Stangor, 1987:597-598; Eagly \& Chaiken, 1993:278-280).

In this article, two experiments are presented. The first experiment is devoted to the question of whether a popular text structure, the problem-solution structure, is capable of capturing the readers' attention. Attention is, however, no guarantee for persuasion. According to McGuire's (1972) information-processing paradigm, the attention process has to be followed by comprehension and yielding processes. Comprehension and yielding can both be influenced by the problem-solution structure as well. Whether it does, was studied in the second experiment. 


\section{Hoeken}

\section{Reading as a kind of exploratory behavior}

Reading a text can be regarded as a kind of exploratory behavior. The reader explores an object, that is, the text. Berlyne (1960) distinguishes two types of exploratory behavior: specific exploration and diversive exploration. Specific exploration is caused by uncertainty on the part of the reader. For instance, someone knows that the previous evening an important baseball game has been played but does not know the result. The uncertainty about the result leads to curiosity. To satisfy this curiosity, the reader searches actively for information about the result. Specific exploration is, thus, aimed at satisfying curiosity through the active search for relevant information.

Diversive exploration, on the other hand, is the result of boredom. When people are deprived of stimuli, they search for entertainment. For instance, with only the paper at hand, one may eventually find oneself reading the stock market reports on a long journey by train. Frijda (1986:346-348) gives the following account of this behavior. When an organism is healthy and free of worries, it has an extra capacity to cognitively assimilate new or unexpected stimuli. When this capacity is not used for some time (e.g., due to sensory deprivation), the organism will actively search for such stimulation. Successful cognitive assimilation of the new stimulus is a pleasant experience, unsuccessful assimilation is an unpleasant one. According to Frijda, the goal of this operation is the functioning of cognitive assimilation itself. Following this line of reasoning, readers pay attention to a text in order to assimilate information.

There can be, therefore, two reasons for reading an advertisement: First, a reader considers the purchase of the product described in the ad, and therefore searches for information about its attributes (specific exploration). Second, one is bored and looking for entertainment (diversive exploration). In the latter situation, the ad has many competitors because usually it is presented within the context of articles and other ads. Copywriters use several strategies to capture the readers' attention, one of which is the use of the problemsolution structure.

\section{Problem-solution structures and exploration effects}

The following ad appeared in a Dutch magazine:

Getting old and enjoying a long life

A dog is a friend for life. Affection, good care, and physical exercise, that's what a dog needs. And of course - just like man - protection against illness. Ask your vet for advice on attending to your dog's old age. Because at an elderly age, blood circulation may decline. This does not go unnoticed: slowness, a dull dry coat and loss of hair, stiffness, and loss of appetite, can result.

Fortunately, these infirmities of old age can be eased by [product] of [company]. It stimulates the heart because it strengthens the heart and reduces the resistance in the lesser blood vessels. [Product] has been specifically developed for veterinary applications, and has proven very effective in practice. Ask your vet. 
[Company] has been a household word in medicine for over 125 years, and has invested more than one billion guilders in medical research. For many plagues and illnesses have not yet disappeared. The efforts needed are examples of [Company].

[Company, address, and telephone number]

This ad is a so-called corporate-image advertisement. Companies use ads such as the one above to be well-known, well-liked, and considered as potential suppliers of goods or services. The ad starts with information about dogs. The writer probably assumed that readers with an interest in dogs outnumber those with an interest in medical research. The information about the dog is not selected randomly, but describes the health problems of the elderly dog. The solution to these problems is presented in the section about a medicine that eases these problems. The last part of the ad describes the company as the one that brought about the solution.

Hoey (1983:83) states that the problem-solution structure is often used in ads. This popularity may be explained by its capacity to capture the reader's attention. First, the problem is about an issue the reader is probably more interested in than in information about the company the ad is about. If this is correct, the chance that readers will select this ad for diversive exploration is higher than if the ad were to start with company information. Next, the problem creates uncertainty and makes the reader curious about the solution. Therefore, the reader searches for information in order to satisfy this curiosity, information which is presented in the solution.

However, it should be kept in mind that it is the information about the company the writer is trying to communicate. The problem-solution information is less important in this respect. In the ad, the company information follows the problem-solution information. It is possible that after reading the solution, readers are interested in the company that provided the solution, and therefore continue reading. However, there is also the possibility that readers stop reading after they have read the solution because their curiosity has been satisfied. Hidi and Anderson (1992:223) note that "curiosity has been traditionally associated only with quite short-term states of uncertainty that could normally be represented by a simple question. Once an answer is provided, uncertainty is reduced and so is curiosity." If so, readers stop after reading the solution, and the use of the problem-solution structure to capture the readers' attention has failed because the company information has not been read.

The company information can be positioned in between the problem and the solution information. If the problem makes readers curious about the solution, they will not stop reading until they have reached that solution. If the company information intervenes between the problem and solution information, they will read that as well. ${ }^{1}$ If, on the other hand, the problem information does not evoke curiosity, readers stop reading as they encounter the company information. Before reaching the company information, some readers will already have stopped reading. Thus, the number of readers paying atten- 
tion to the company information will be smaller when this information follows the problem information than when it precedes the problem information. Therefore, if the problem information does not evoke specific exploration, the company information receives more attention if it precedes the problem-solution information than in any other position. If readers have little time to read, they will read less of each text. Under such conditions, the effect that the company information receives more attention when positioned first, will be particularly strong.

Summarizing, one can increase the chance that a corporate image ad is read as a result of diversive exploration by starting the ad with a more interesting topic than the company information. Therefore, hypothesis 1 is: If the ad starts with problem information, more attention is given to the ad than if it starts with company information.

The most important information in the ad is about the company. If the problem-solution structure is capable of evoking specific exploration, the chances that readers pay attention to the company information are higher when they encounter the company information before having satisfied their curiosity than when they encounter it after having satisfied their curiosity. If the problemsolution structure is not capable of evoking specific exploration, the company information receives more attention if it precedes the problem-solution information, in particular if readers do not have the time to read all texts completely. Therefore, hypothesis 2 is: The company information receives the most attention if it precedes the problem-solution information and the least attention if it follows the problem-solution information, in particular if the opportunity to read is restricted.

\section{Experiment 1 \\ Method}

Materials. The content of the experimental texts were provided by 19 corporate-image advertisements that had actually appeared in Dutch magazines. Three versions of each text were written, which differed in the positioning of the section containing information about the company. This section either came first, followed by the problem and solution sections (company-problemsolution); second, positioned between the problem and solution sections (problem-company-solution); or third, preceded by the problem and solution sections (problem-solution-company). Each of the three parts, problem, solution, and company, consisted of five sentences. In each version, the sections were identical with the exception of the first sentence of the problem section for some of the texts. If the problem section followed the company-section, the first sentence had to be slightly altered in order to keep the text natural. The sentence ' $\mathrm{He}$ who administers himself a fortune possibly has a lot of sleepless nights', for example, was altèred into 'Because he who administers himself a fortune possibly has a lot of sleepless nights' if it followed the company information. In each text, the company name was replaced by a fictitious one. 
The texts were pretested on several aspects. First, 21 participants rated the texts' naturalness. Using a Latin square design, each participant saw all nineteen texts but only one version of each text. Participants rated the text's naturalness on a seven-point scale. Furthermore, it was tested whether the sections were indeed regarded as describing a problem, a company, or a solution. Therefore, participants were asked to indicate for each section whether they thought it was the problem, the solution, or the company section. A fourth possibility, 'do not know', was included to discourage guessing. With the exception of one text, the texts were judged as natural in any of the three versions as was indicated by the minimum score of 4.27 and the maximum score of 5.83 on a seven-point scale ranging from 1 (unnatural) to 7 (natural). The only text that scored below the scale's neutral midpoint $(M=3.86)$ was excluded from the experiment. Three more texts were excluded because less than 15 participants were able to identify the three sections correctly. This led to the selection of 15 experimental texts.

In a second pretest, it was checked whether the first sentence of the problem-section evoked more curiosity than the first sentence of the companysection. To this end, 15 sets of four first sentences of ads were created. In each set, the first sentence of the company-section as well as the first sentence of the problem-section were included together with two other first sentences of ads. Fifty participants were asked to rank the four sentences from 'most curiosity evoking' to 'least curiosity evoking'. There were two versions of the booklet that differed with respect to the order in which the first sentences of the problem- and company-section were presented. For each set, half of the participants read the first sentence of the problem-section before that of the company-section, whereas the other half received the sentences in the reversed order. Within each booklet, the order in which the company and problem sentences were presented was varied. The results were analyzed using the Wilcoxon matched-pairs test. For each text, the first sentence of the problem-section was rated as significantly more curiosity evoking than the first sentence of the company-section.

In addition to the fifteen experimental texts, seven filler texts were used. These texts were corporate-image advertisements consisting of fifteen sentences, containing company information only.

Participants. Forty-eight people participated in the experiment, 33 women and $15 \mathrm{men}$. They were not paid for their participation. Their ages ranged from 18 to 47 , with a mean of 23 . All participants had completed high school, at least.

Design. Each participant read five experimental texts with a CompanyProblem-Solution structure (C-P-S), five texts with Problem-CompanySolution structure (P-C-S), and five texts with a Problem-Solution-Company structure (P-S-C), all of which were about different companies. The different versions were distributed evenly across the presentation order. The different versions of each text were presented equally often but to different participants. 
This resulted in three presentation lists. Half of the participants were told that they had only five minutes to read the texts (restricted opportunity), the other half were told that they could read as long as they wanted (unrestricted opportunity).

Procedure. Participants received a written instruction. They were instructed to imagine they were traveling by train to attend a meeting at which several companies would give business presentations. To orient themselves, they had received a brochure containing information about the participating companies. It was stressed that they did not have to read all of the texts completely, but could switch to the next text as soon as they were no longer interested in the current one. Half of the participants were told that they had plenty of time before their arrival (unrestricted opportunity), the other half were told that in five minutes they would reach their destination (restricted opportunity). The participants in the restricted opportunity condition received a stopwatch indicating the time left.

The texts were presented on an Ms-Dos computer using a monochrome monitor (foreground white, background black). The first screen displayed information on how the texts were to be presented. It stated that before each text the phrase 'New text' would appear on the screen. This phrase would automatically disappear after two seconds, upon which the first sentence would be presented. Participants could choose to read the next sentence of this text by pressing ' 1 ' on the keyboard, or they could choose to switch to the next text by pressing ' 0 ' on the keyboard. If they chose the next sentence, the first sentence would be replaced by the second one immediately, and the participant could again choose between the next sentence or the next text. If participants chose to switch to the next text, the phrase 'new text' was displayed for two seconds upon which the first sentence of the following text was presented.

For the participants to get used to this way of presentation, the first three texts were practice texts (without the participants being aware of this). These were followed by the fifteen experimental texts that were divided into five blocks of three texts. Each block of three texts contained the three different structure versions, and was separated from the next block by one filler text. The number of sentences read and the time spent on each text were recorded as measures of the amount of attention given. After the session, participants were informed of the goal of the experiment and any questions they had were answered. Experimental sessions lasted for about 25 minutes each in the unrestricted opportunity condition, and for about 15 minutes each in the restricted opportunity condition.

Statistical analyses of the data. Due to a hardware problem, the results of three participants in the restricted opportunity condition were lost. In the restricted opportunity condition, some participants did not get to read all of the texts because of the time limitation. Unread texts were excluded from the analysis. ${ }^{2}$ For each of the remaining texts, the number of sentences read and time spent was summated for the whole text as well as for the block containing the 
company information. Following the discussion by Clark (1973), two two-way analyses of variance were carried out on the data for each of the dependent variables, one with subjects as random factor $\left(F_{1}\right)$ and one with texts as random factor $\left(F_{2}\right)$. In the two analyses, the structure factor contained repeated measures. Opportunity contained repeated measures in the stimulus analysis $\left(F_{2}\right)$, but not in the subjects analysis $\left(F_{1}\right)$. An alpha level of .05 was used for all statistical analyses.

Results

Tests of the hypotheses. Hypothesis 1 stated that more attention would be paid to a text starting with the description of the problem. Table 1 contains the mean number of sentences read and the mean reading time as a function of structure and opportunity.

Table 1: Mean Number of Sentences Read and the Mean Reading Time (in seconds) as a Function of Structure and Opportunity

\begin{tabular}{ccccc}
\hline & \multicolumn{4}{c}{ Structure } \\
& $\mathrm{n}$ & P-S-C & P-C-S & C-P-S \\
\hline $\begin{array}{c}\text { Number of sentences } \\
\text { Unrestricted }\end{array}$ & 24 & & & \\
M & & 10.98 & 10.44 & 6.66 \\
SD & 21 & 2.82 & 3.30 & 4.30 \\
Restricted & & 5.72 & 6.30 & 3.47 \\
M & & 2.69 & 2.80 & 2.76 \\
SD & & & \\
Reading time & & & & \\
Unrestricted & 24 & 26.92 & 26.75 & 16.86 \\
M & & 7.80 & 8.34 & 10.46 \\
SD & & & & \\
Restricted & 21 & 13.35 & 16.15 & 8.86 \\
M & & 6.64 & 10.16 & 7.06 \\
SD & & & & \\
\hline
\end{tabular}

Note: Minimum number of sentences read is 1 , maximum number is 15 .

The results supported the hypothesis. There was a main effect of structure on the number of sentences read, $F_{1}(2,86)=26.54, p<.001, F_{2}(2,28)=20.24$, $\mathrm{p}<.001$, and on the time spent $F_{1}(2,86)=19.60, p<.001, F_{2}(2,28)=19.70$, $\mathrm{p}<.001$. Comparisons revealed that when the ad started with a problem description (P-S-C and P-C-S versions) more sentences were read than when the ad started with information about the company. When the time to read was restricted, fewer sentences were read, $F_{1}(1,43)=32.40, p<.001, F_{2}(1,14)=$ $162.36, p<.001$, and less time was spent than in the unrestricted condition, $F_{1}$ $(1,43)=31.67, p<.001, F_{2}(1,14)=115.37, p<.001$. There were no significant 
interactions between opportunity and structure for the number of sentences read, $F_{1}(2,86)=1.98, p=.15, F_{2}(2,28)=2.88, p=.07$, or for the time spent, $\mathrm{F}_{1}(2,86)=1.77, \mathrm{p}=.18, \mathrm{~F}_{2}(2,28)=2.95, \mathrm{p}=.07$.

Hypothesis 2 stated that the company information would receive the most attention if it preceded the problem-solution information and the least attention if it followed the problem-solution information. Table 2 contains the mean number of sentences read and the mean time spent on the block with company information as a function of structure and opportunity.

Table 2: Mean Number of Sentences Read and the Mean Reading Time (in seconds) for the Company Information as a Function of Structure and Opportunity

\begin{tabular}{ccccc}
\hline & \multicolumn{2}{c}{ Structure } \\
& $\mathrm{n}$ & P-S-C & P-C-S & C-P-S \\
\hline $\begin{array}{c}\text { Number of sentences } \\
\text { Unrestricted }\end{array}$ & 24 & & & \\
M & & 2.36 & 3.43 & 3.32 \\
SD & & 1.37 & 1.28 & 1.38 \\
Restricted & 21 & & & \\
M & & 0.55 & 1.86 & 2.51 \\
SD & & 0.84 & 1.27 & 1.69 \\
Reading time & 24 & & & \\
Unrestricted & & & & \\
M & & 5.44 & 8.55 & 8.88 \\
SD & 21 & 3.46 & 3.38 & 3.87 \\
Restricted & & 1.08 & 4.66 & 6.61 \\
M & & 1.59 & 4.12 & 4.72 \\
SD & & &
\end{tabular}

The hypothesis was partly supported. There was a main effect of structure on the number of sentences read, $F_{1}(2,86)=21.55, p<.001, F_{2}(2,28)=19.18$, $p<.001$, and on the time spent, $F_{1}(2,86)=25.64, p<.001, F_{2}(2,28)=24.30$, $\mathrm{p}<.001$. Planned comparisons revealed that only when the company information followed the problem-solution structure, were fewer sentences read and less time spent. Comparisons revealed no significant difference between the number of sentences read and the time spent on the P-C-S version and the C$\mathrm{P}-\mathrm{S}$ version. Furthermore, structure and opportunity did not interact for the number of sentences read, $F_{1}(2,86)=2.43, p=.09, F_{2}(2,28)=1.87, p=.17$, or the time spent, $\mathrm{F}_{1}(2,86)=1.41, \mathrm{p}=.25, \mathrm{~F}_{2}<1$.

Ruling out a reading goal explanation. It could be argued that the instruction participants received was responsible for this pattern of results. That is, participants were told to orient themselves concerning the advantages of the various companies. Therefore, they were searching for company information. 
If this information appeared at the beginning of the text, their goal was reached sooner than when it appeared in the middle of the text. In the latter case, participants had to read more sentences. When the information appeared at the end of the text, participants may have given up on attaining their goal. To pit this reading goal model against the exploration model, three comparisons were done for which the two models made different predictions.

The first comparison concerned the proportion of participants who stopped reading after the first sentence. The reading goal model predicts that this proportion is the same for all text versions; by reading the first sentence of the problem information the participants do not reach their goal and it is unlikely that reading the first sentence of the company information gives them enough information to form their impression of the company. The exploration model makes a different prediction: If the first sentence is about the company, more readers stop reading than if the first sentence is about the problem. The first sentence of the problem was about a topic that more readers were interested in thereby increasing the chance of diversive exploration. The results showed that the proportion of readers who stopped reading after the first sentence of the company information $(M=.43, S D=.40$ ) was almost three times as large as the proportion who stopped reading after the first sentence of the problem information (M $=.15, \mathrm{SD}=.19), \mathrm{F}_{1}(1,43)=31.02, \mathrm{p}<.001, \mathrm{~F}_{2}(1,14)=109.54, \mathrm{p}<.001 .^{3}$

It could be argued that reading the first sentence of the company information is sufficient for getting an idea about the company, that is, after reading this first sentence readers have attained their goal. The knowledge that a given company is an insurance company, for example, could be enough information for participants to decide that they do not want more information about it. In that case, the reading goal model predicts that the proportion of participants who stop reading after the first sentence of the company information is the same regardless of whether it is the first sentence of the text (C-P-S version) or whether it was the first sentence after the problem information (P-C-S version). In both situations, the reader's goal is reached. The exploration model, on the contrary, predicts that the proportion of readers who stop reading after the first sentence of the company information is larger when this sentence is the first sentence of the text (C-P-S version) than when it follows the problem information (P-C-S version). In the latter version, the problem has aroused the readers' curiosity and they keep reading until they have read the solution whereas in the former version there is no question of such specific exploration. Again, the results supported the exploration model but not the reading goal model: The proportion of readers who stopped after reading the first company information sentence in the $\mathrm{C}$ $\mathrm{P}-\mathrm{S}$ version $(\mathrm{M}=.43 . \mathrm{SD}=.40)$ was again almost three times as large as the proportion who stopped after reading the same sentence in the P-C-S version $(M=$ $.15, \mathrm{SD}=.26), \mathrm{F}_{1}(1,43)=18.30, \mathrm{p}<.001, \mathrm{~F}_{2}(1,14)=22.18, \mathrm{p}<.001 .^{4}$

The third comparison was between the proportions of readers who stopped reading after the first sentence of the problem information when this information came first (P-C-S and P-S-C versions) and those who stopped after the 
first sentence when the problem information followed the company information (C-P-S version). The reading goal model predicts that in the latter case more readers stop reading because they have reached their goal after reading the company information, whereas in the former case they keep on reading because they have not yet received information about the company. The exploration model predicts no differences because in both situations the first sentence of the problem is equally interesting. The results showed no significant differences between the proportion of readers who stopped after reading the first problem-description sentence when this sentence was the first sentence of the text $(M=.10, S D=.16)$ and when this, sentence followed the company information $(\mathrm{M}=.19, \mathrm{SD}=.33), \mathrm{F}_{1}(1,25)=2.34, \mathrm{p}=.14, \mathrm{~F}_{2}<1$. Thus, in all three comparisons, the predictions made by the reading goal model were rejected whereas those of the exploration model were supported.

\section{Discussion}

The results support the first hypothesis about diversive exploration: Ads starting with the company information received less attention than ads starting with a more interesting topic. These results could not be explained by a reading goal model as was evidenced by three further comparisons. The results about the attention given to the company information showed that problemsolution structures can evoke specific exploration. That is, readers were willing to pay attention to the company information when it was positioned between the problem and solution information because they were interested in the solution. When the company information followed the problem and solution sections, it received less attention because the curiosity evoked by reading the problem had been satisfied by reading the solution. On the basis of these results, the effects of the problem-solution structure can be described as stimulating diversive exploration by describing a problem about a more interesting topic than the company, and evoking specific exploration by making the readers curious about the solution.

Attention is a necessary prerequisite for persuasion, but not a sufficient one. The results of Experiment 1 show that the problem-solution structure can capture the readers' attention, but they cannot answer the question which effects the problem-solution structure has on the comprehension of, and yielding to the text. The ads used are written to achieve three goals: (1) recognition of the company's name, (2) creation of a positive image of the company, (3) formation of an intention to patronize the company's services (Rossiter \& Percy, 1987:410). What effects can the use of the problem-solution structure have on these objectives? If it influences the recognition and yielding processes, it is the information contained in the problem and solution sections that can influence these processes. Therefore, the label problem-solution information will be used in the presentation of Experiment 2.

First, the possible effects on the storage of information will be discussed. The presence of problem and solution information may divert the reader's 
attention from the company information. This diversion effect will be especially strong when the problem and solution information is emphasized by the text structure. Kieras $(1980,1981)$ reported that positioning information at the beginning of the text is interpreted as a signal of its importance. This implies that when the ad starts with the problem information, its importance is emphasized. If, on the other hand, the ad starts with the company information, this information receives emphasis. According to Reynolds and Shirey (1988), perceived importance is a good predictor of whether information will be stored in memory. Therefore, company information is remembered better if it precedes the problem-solution information, than if it is positioned between the problem and the solution information, or follows them.

With regard to the effect of different structures on the ad's persuasiveness, it is difficult to make strong predictions. The same information is presented in each of the three structure versions, so the arguments are identical. The only difference between the versions is the relative emphasis each of the sections receives as a function of its position in the text. It is more interesting to compare the persuasive impact of the ads containing problem-solution information with a version containing only the company information. Until this point, the information expressed in the problem-solution structure has been described as a means of attracting the reader's attention, but it can also be interpreted as a persuasive argument. The problem-solution information can function as an example of the types of problem the company deals with, and the ingenuity of the solutions it provides. As such, the content of the problem-solution information can function as an argument to corroborate the claim that the company should be evaluated positively. In that case, an ad containing problem-solution information is more persuasive than an ad containing only the company information.

Summarizing, the initial position in a text is taken by readers to stress the importance of this information (Kieras, 1980, 1981). If the goal of the ad is to inform its readers about the company, it would be more effective to start the ad with the company information than to start it with the problem information. This leads to hypothesis 3: If the ad starts with the company information, this information is stored more effectively in memory than if the advertisement starts with the problem information.

The presence of a problem-solution structure can increase the ad's persuasiveness relative to one containing only company information. The problemsolution information can function as an argument by giving a concrete example of the company's ingenuity. This leads to hypothesis 4: A corporate-image advertisement containing problem-solution information is more persuasive than an advertisement containing only company information.

\section{Experiment 2}

Method

Materials. Not all of the fifteen experimental texts used in Experiment 1 could be used in this experiment. The selected ad had to demonstrate strong 
exploration effects. To this end, the results from Experiment 1 were analyzed for each text separately using two-way analyzes of variance with structure (P-C-S, P-S-C, C-P-S) and opportunity (unrestricted, restricted) as betweensubjects variables. Four texts showing the strongest specific and diversive exploration effects were selected and entered into a pretest of the material. Nineteen participants rated each text for interestingness on a seven-point scale ranging from 1 (uninteresting) to 7 (interesting). Three experimental texts had similar interestingness ratings ( $M$ 's ranging from 2.42 to 2.68 ). The fourth text was judged as markedly more interesting than the others $(M=4.21)$. Therefore, it was excluded from the experiment.

Hypothesis 3 is based on the assumption that the information that is provided first will be perceived as relatively more important. To test this hypothesis, a text had to be selected in which the position of the information affected its importance ratings. To this end, the three ads were entered into a second rating experiment. Each sentence of each ad in each structure was rated for importance and interestingness.

A total of 72 people participated in the rating experiment. A Latin square design was employed: Each participant rated all three structure versions but with each structure version of a different ad. Furthermore, each version of an ad was presented equally often but to different participants. Directly upon reading a sentence, participants had to rate its interestingness and its importance on separate seven-point scales ranging from 1 (uninteresting or unimportant) to 7 (interesting or important). Mean interestingness and importance scores were computed for each information-type block based on the scores for the five individual sentences. The interestingness and importance scores were analyzed separately for each text using two-way analysis of variance with structure (P-S-C, P-C-S, C-P-S) and information type (company, problem, solution) as factors. The information type factor contained repeated measures, because each participant rated the interestingness and importance of the problem, the solution, and the company information.

If the position of the information affects its importance and its interestingness, an interaction between structure and information type should arise. There was only one text for which this interaction arose for the importance data, F (4, $138)=4.32$, $\mathrm{p}<.01$, as well as the interestingness data, $\mathrm{F}(4,138)=4.48, \mathrm{p}<.01$. When the problem was mentioned first (P-S-C, P-C-S), it was rated as more important and interesting than when it was mentioned second (C-P-S). Similarly, the company information was rated as less important and less interesting when it was positioned at the end of the ad. This text was selected for the experiment, and was about a medical research company. (The experimental text may be found in the Appendix to this article.) To test hypothesis 3, the effect of information position on memory storage was assessed; to test hypothesis 4 , the effect of including problem-solution information on the yielding process was studied.

Participants. A total of 216 people participated in the experiment (108 women, 108 men). They were recruited by students as part of a course fulfill- 
ment, and they were not paid for their participation. Their age ranged from 17 to 51, with a mean of 24. All participants had completed at least high school.

Questionnaire. The questionnaire contained the following variables: general questions, the attitudes toward working for the company and the company's products, the intentions to gain employment with the company and to purchase the company's products, the company's image, beliefs about the company's excellence, the perceived comprehensibility and attractiveness of the text, text recognition, and reproduction of the company name. This order reflects the order in which the questions were asked. The texts were presented following the general questions.

The attitude, intention, image, and beliefs were used as indications of the text's persuasiveness. The text recognition and reproduction items were used as a measure of the amount of information stored. Perceived comprehensibility and attractiveness of the text were included to back up the plausibility of the instruction. (Participants were told that the study was about text appreciation.) The operationalization is discussed for each variable.

General questions. Participants were asked whether they regularly read advertisements in magazines and papers, whether they liked animals and dogs, and the extent to which they enjoyed thinking about information.

The attitudes towards working for the company and the company's products. The attitude towards working for the company was measured using four seven-point semantic differentials which were preceded by the phrase 'Working for Medicinaal Inc. seems to me:'. A balanced scale was used: Two of the four differentials had the positive antonym at the lefthand pole of the scale (nice, positive), the other two had the positive antonym at the right-hand pole (wise, interesting). The reliability of the scale was adequate (Cronbach's $\alpha=.79$ ). The attitude towards the company's products was measured using the same procedure. The four differentials were preceded by the phrase 'The products developed by Medicinaal Inc., seem to me:'. The reliability of the scale was good (Cronbach's $\alpha=.88$ ).

The intentions to gain employment with the company and to purchase the company's products. The intention to gain employment with the company was measured using three seven-point Likert scales ranging from 1 (strongly disagree) to 7 (strongly agree). The statements were: 'I want to know more about the possibilities of working for Medicinaal Inc.', 'After my graduation, I will send an application to Medicinaal Inc.', and ' $I$ would like to work for Medicinaal Inc.' The reliability of the scale was good (Cronbach's $\alpha=.89$ ). The intention to purchase the company's products was measured using the same procedure. The statements were ' $I$ would like to know more about the various Medicinaal Inc. products', 'I regard the Medicinaal Inc. products as excellent in this class of products', and 'I would rather purchase a Medicinaal Inc. product than a similar product of another company.' These three items did not yield a reliable scale (Cronbach's $\alpha=.57$ ), and, therefore, the items were entered separately into the analysis. 
The company's image. The company's image was measured using a balanced scale containing twelve seven-point semantic differentials with antonyms such as, reliable, attractive, unprofessional, and inefficient. The reliability of the scale was good (Cronbach's $\alpha=.87$ ).

Beliefs about the company's excellence. Three beliefs about the company's excellence were measured using seven-point Likert-scales. The three statements were: 'Medicinaal Inc. is a big shot in medical science', 'Medicinaal Inc. leads the way in the development of new medicines' and 'A lot of highly qualified researchers work for Medicinaal Inc.'

The perceived comprehensibility and attractiveness of the text. The dimensions of comprehensibility and attractivity were measured using a balanced scale consisting of six seven-point semantic differentials. The items of the two dimensions appeared in random order. The reliability of the scales was at least adequate (Comprehension: Cronbach's $\alpha=.74$; attractiveness: Cronbach's $\alpha$ $=.86$ ). The items were used to support the instruction's plausibility. The results were not relevant to the hypotheses, and are, therefore, not reported.

Text recognition. Eight assertions were made about the ad, four of which were about the company. Participants had to indicate whether the assertion was right or wrong, and whether they were certain or uncertain about their answer. Half of the assertions were correct and the others were incorrect. The number of wrong answers the participant indicated $s / h e$ was sure about, was subtracted from the number of right answers $s /$ he was sure about. The resulting score was divided by the total number of items on the company information (4). The proportion thus obtained is the text recognition score corrected for guessing (Sax, 1980).

Reproduction of the company name. After completing the questionnaire, the participants returned it to the experimenter. They were then asked to reproduce the name of the company. Their answer was written on the questionnaire.

Design. A between-subjects design was used, that is, participants read only one version of the ad and were afterwards asked their opinion of the company. There were three experimental booklets containing the different structure versions (P-S-C, P-C-S, C-P-S), and a fourth experimental booklet in which an ad was presented that contained only the company information. The latter was necessary to test hypothesis 4 about the persuasiveness of the ads including the problem-solution structure versus the ad containing only company information.

Procedure. Participants took part individually. Participants were told that the Linguistics department of Tilburg University was investigating the quality of texts in which companies present themselves. The study the participants would take part in was about their appreciation of one of these texts. After this introduction, participants received the experimental booklet. On the front page it said: Project 'Text appreciation'. The first page contained instructions on how to fill out the item types, followed by the general questions. The next page contained one of the experimental text versions (P-S-C, P-C-S, C-P-S), or, in the fourth booklet, by the company information only. In this booklet, the infor- 
mation was preceded by the statement that the appreciation of the text could be affected by the participant's opinion about the company described, and, therefore, a number of questions about the company had to be asked first, after some information about the company had been provided. Next, the company information was presented. Subsequently, the questions about the attitude, intention, beliefs, and company's image were asked in all of the versions. After turning the page, the left-hand page contained a repetition of the text version while the right-hand page contained the questions about the text's comprehensibility and attractiveness. In the case of the company-information-only condition, the C-P-S version was presented. The last page contained the textrecognition items. Participants were not allowed to turn back to the text. After completing the experimental booklet, they handed it in and were asked the company name. Then, participants were told about the true purpose of the experiment and were thanked for their cooperation. An experimental session lasted about 15 minutes.

Statistical analyses of the data. Before analyzing the results, all negatively formulated Likert-scales and semantic differentials with the positive antonym at the left pole were recoded. Hypothesis 3 about the effect of the company position on the recognition of company information, was tested using the non-parametric Mann-Whitney $U$ test. ${ }^{5}$ The results on retaining the name of the company were tested using the chi-square test. Hypothesis 4 about the persuasiveness of the advertisements was tested using a MANOVA with problem-solution (present, absent) as between-subjects factor. A MANOVA was used because the attitude, intention, image and belief scores were correlated. An alpha level of .05 was used for all statistical analyses.

\section{Results}

Hypothesis 3 stated that the company information in a corporate-image advertisement would be stored more effectively in memory if the advertisement started with the company information than if it started with a problem description. The hypothesis was confirmed. Participants reading the ad starting with the company information scored higher on the recognition items about the company information $(M=.61, S D=.44)$ than participants reading the ad starting with the problem description $(\mathrm{M}=.47, \mathrm{SD}=.43, \mathrm{z}=1.83, \mathrm{p}<.05$, one-tailed test). The reproduction of the company name was not affected by the position of the company information in the ad. Regardless of position, $66.5 \%$ of the subjects succeeded in reproducing the company name, $\chi^{2}(1, N=158)=$ $0.01, \mathrm{p}=.94$.

Hypothesis 4 stated that a corporate-image advertisement containing problem-solution information would be more persuasive than an advertisement containing only company information. There was, indeed, a main effect of problem-solution information, Wilks' $\lambda=.89, \mathrm{~F}(10,203)=2.45, \mathrm{p}<.01$. Separate univariate analyses revealed two significant effects. The directions of these effects were, however, opposite to that which was predicted: Absence of 
the problem-solution information yielded a more positive attitude toward the products $(M=5.13, \mathrm{SD}=.96)$ compared to the versions containing the problem-solution information $(\mathrm{M}=4.73, \mathrm{SD}=1.22), \mathrm{F}(1,212)=4.63, \mathrm{p}<.05$, and a more positive belief about the number of qualified researchers $(M=5.35$, SD $=1.12$, vs. $\mathrm{M}=4.98, \mathrm{SD}=1.16), \mathrm{F}(1,212)=4.10$, $\mathrm{p}<.05$.

The inclusion of the problem-solution information did not make the text more persuasive but even less persuasive. It led to a less positive attitude toward the products of the company and to a less positive belief about the number of qualified researchers working for the company. This negative effect of inclusion of the problem-solution information may have been caused by its content. Reading only the company information may have given the impression that the company developed medication for humans, whereas the problem description of a canine's health problems gave the impression that the company developed medication solely for animals. If people judge medication for humans as being more valuable than medication for animals, this could explain the more positive attitude toward the company's products when only the company information was read. Along the same line of reasoning, readers may rate researchers developing medication for humans as better qualified than researchers developing medication for animals. To test this explanation, a control experiment was conducted.

Forty-nine people participated in the control experiment, 40 women and 9 men. Age ranged from 19 to 41, with a mean of 22. Each participant received a booklet. First, participants were asked to rank four products from most important to least important. These four products were medication for people, equipment for the handicapped, baby food, and medication for animals. Next, participants were asked to rank four types of researchers from highest qualified to lowest qualified. The types of researchers were: researchers on medication for animals, researchers on baby food, researchers on equipment for the handicapped, and researchers on the medication for people. In a second version of the booklet, the order of the alternatives was reversed. Finally, participants had to read one of the text versions (either the problem-company-solution version or the company-information only version). After reading, they had to indicate on a five-point scale ranging from 1 (very unlikely) to 5 (very likely) the likelihood that the company produced medication for humans and on a similar scale the likelihood that the company produced medication for animals.

The results of the rank-ordering were analyzed using the nonparametric Wilcoxon matched pairs test. The results of the likelihood manipulations were analyzed using a two-way analysis of variance with text version (P-C-S, C) and type of medication (for people, for animals) as factors. The type of medication factor contained repeated measures. The results showed that medication for people was rated as more important than medication for animals $(z=$ 5.93, $\mathrm{p}<.001)$. Similarly, researchers on medication for people were rated as more qualified than researchers on medication for animals $(z=5.50, p<.001)$. Table 3 contains the mean perceived likelihood of the company producing 
medication for animals or for people as a function of the inclusion of the problem-solution information.

Table 3: Mean Likelihood of the Company Producing Medication for Animals or for People as a Function of the Inclusion of the Problem-solution Information

\begin{tabular}{cccc}
\hline & \multicolumn{3}{l}{ Likelihood that Company Produces Medication for } \\
& $\mathrm{n}$ & Animals & People \\
\hline $\begin{array}{c}\text { Problem-solution Information } \\
\text { Included } \\
\text { M }\end{array}$ & & & \\
SD & 25 & 4.28 & 2.88 \\
Excluded & & 1.02 & 1.17 \\
M & 24 & & 4.33 \\
SD & & 2.79 & 0.56 \\
\hline
\end{tabular}

Note: Judgements were made on 5 -point scales $(1=$ very unlikely, $5=$ very likely).

There were no main effects of inclusion of problem-solution information $(\mathrm{F}<1)$, or type of medication $(\mathrm{F}<1)$. There was however a strong interaction between the inclusion of problem-solution information and type of medication, $\mathrm{F}(1,47)=54.16, \mathrm{p}<.001$. Planned comparisons revealed that inclusion of the problem-solution information decreased the perceived likelihood that the company produced medication for humans and increased the perceived likelihood that the company produced medication for animals. Exclusion of the problem-solution information led to the opposite result. These results support the interpretation that the negative persuasive effect of the inclusion of the problem-solution information is to be attributed to a different perception of the company's core business.

\section{Discussion}

The results confirmed the hypothesis that company information is stored more effectively in memory if it is positioned at the beginning of the text. Kieras (1981) found a similar effect of initial mentioning of information on the recall of this information for schoolbook texts. The position of the company information did not affect the reproduction of the company name. This might be caused by the fact that the name of the company was repeated in many of the items used to measure the persuasiveness of the text as well as in the recognition items. This constant repetition of the company name may have obscured the effect of the initial positioning of the company information.

The hypothesis that inclusion of the problem-solution information would result in a more persuasive text had to be rejected. Instead, including this information gave readers the impression that the company developed medication 
for animals which, in turn, led to a lower evaluation of the company's products and the number of qualified researchers employed. Due to differences in perception of the company's core business, the inclusion of the problem-solution information led to a less persuasive text.

\section{General discussion}

Many experiments have been conducted on the effects of different text characteristics on the yielding process without taking into consideration that these characteristics may affect the attention and comprehension processes as well. In this study, two experiments are reported that did just that: Studying the effect of the problem-solution structure on the attention as well as the comprehension and yielding processes. The results of this study underscore the importance of such research. Positive effects on one of the processes, do not guarantee similar effects on the others. Starting the ad with problem information increased attention for the ad, but at the same time, decreased the recognition of its most important information: the information about the company. Furthermore, inclusion of the problem-solution information decreased the ad's persuasiveness because it gave readers the wrong impression of the company's core business. If the copywriter had selected a better example of the company's achievements, inclusion of the information may have made the text more persuasive, but that is not the issue here: The issue is that text characteristics which have been shown to have a positive effect on one of the processes may have a negative effect on others.

In studying the effect of the problem-solution structure on the attention process, Berlyne's (1960) distinction between specific and diversive exploration proved very useful. Starting an ad with the description of a problem led to diversive exploration, which spurred the readers' curiosity as to the solution after they had read the problem thereby inducing specific exploration. In the experiment, the texts were presented sentence by sentence on a computer screen. Therefore, participants were not able to reread preceding sentences or jump to a new paragraph. The sentence-by-sentence procedure was used because it provided a precise measure of which sentences were attended to and for how long. Wade, Schraw, Buxton and Hayes (1993) showed that such a presentation mode did not lead participants to adopt a reading strategy different from the one they would normally employ. They replicated an experiment by Wade and Adams (1990) using a sentence-by-sentence presentation on a computer. Wade and Adams had presented the same text on paper. The two studies revealed similar recall effects which suggests that the sentence-by-sentence presentation did not affect the participants' reading strategies. Nevertheless, it would be desirable to replicate the experiment in a less artificial reading situation.

The results of the second experiment showed that starting an ad with a problem description inhibited the storage of the company information in memory. This result is in line with experiments by Kieras $(1980,1981)$ that showed that readers use initial mentioning of a topic as a cue for its importance. As pre- 
dicted, when the company information preceded the problem-solution structure, it was recognized better. Further research is needed to test whether the presence of problem-solution information inhibits the storage of company information, regardless of its position. In several experiments it has been shown that the inclusion of interesting information which is relatively unrelated to the main points of the text leads to a decrease in the recall of the main points (for a review, see Garner, Brown, Sanders \& Menke, 1992). That is, the problem-solution information will be remembered at the cost of the company information because the former are more interesting.

The results of this study underscore the usefulness of McGuire's (1972) information-processing paradigm to understand the way in which text characteristics influence the persuasion process. McGuire takes explicitly into account that factors causing successes in earlier processes may lead to failures in subsequent processes. To fully understand the way in which texts influence the persuasion process, one has to understand what makes readers read them, comprehend them, and yield to them.

\section{Notes}

1 Hidi and Baird (1988) employed such a strategy to increase the interestingness of schoolbook texts. They described a problem followed by a paragraph that preceded the solution. This manipulation led to higher interestingness-ratings compared to a version in which the solution immediately followed the problem information.

2 When computing mean scores for each of the conditions in the $F_{1}$ and $F_{2}$ analyses, these scores were corrected for the number of texts read.

3 The proportions were analyzed using the methods described in section 2.5. Because there were no significant interactions between structure and opportunity for any of the three comparisons, only the main effects of structure are reported, for simplicity's sake.

4 For the second and third comparison, it had to be taken into account that the first sentence of a text was read by all participants but that the sixth sentence could be read only by participants who got that far. Therefore, the proportion of participants who stopped reading after the sixth sentence was related to the number of participants who actually read this sentence. If all participants stopped reading before reaching the sixth sentence, the results of the text were excluded from the analysis.

5 Hypothesis 6 was tested non-parametrically because it concerned proportion scores that typically violate the assumption of homogeneity of variance (Rietveld \& van Hout, 1993:126-127).

Appendix: Experimental text, version: problem, solution, company information

Iedereen wil toch oud worden en lang van het leven genieten

Uw hond loopt, net als uzelf, het risico van allerlei ziekten. Daarom heeft-ie in eerste instantie goede verzorging, lichaamsbeweging en liefde nodig. Maar op oudere leeftijd gaat de kwaliteit van de bloedsomloop toch achteruit. Dat merkt $u$ aan uw hond. Want hij wordt sloom, krijgt een doffe en droge vacht en eet minder.

Medicinaal N.V. heeft een nieuw middel ontwikkeld voor oudere dieren: Karsivan. In de praktijk is het bijzonder effectief gebleken. Het stimuleert de hartfunctie omdat 
het de hartkracht vergroot en de weerstand in de kleine bloedvaten vermindert. Dit middel gaat ouderdomsverschijnselen tegen. Zodat uw hond blijft zoals hij is: uw beste vriend.

Medicinaal N.V. is al meer dan 125 jaar een begrip in de geneeskunde. $\mathrm{Zij}$ investeert jaarlijks meer dan een miljard gulden in medisch onderzoek. In verschillende laboratoria worden geneesmiddelen ontwikkeld. Daarbij wordt steeds contact gehouden met universiteiten, artsen en andere research instellingen. Alleen al in het laboratorium in Hoorn werken meer dan 250 hoog opgeleide researchers aan nieuwe geneesmiddelen.

[translation of text]

Everybody wants to get old and enjoy a long life

Your dog runs, just like you, the risk of catching diseases. That's why he needs affection, good care, and physical exercise. But as he grows older, his blood circulation declines. This does not go unnoticed. Because of his slowness, a dull dry coat and loss of hair, and loss of appetite.

Medicinaal N.V. has developed a new medicine for aging animals: Karsivan. It has proven very effective in practice. It stimulates the heart because it strengthens the heart and reduces the resistance in the lesser bloodvessels. The medicine fights the infirmities of old age. So your dog remains the same: your best friend.

Medicinaal N.V. has been a household word in medicine for over 125 years. It has invested more than one billion guilders in medical research. In laboratories medication is being developed. During the development, contact is maintained with universities, doctors, and research institutes. At the laboratory at Hoorn alone, more than 250 highly qualified researchers are working work at the development of new medications.

\section{References}

Berlyne, D. E. (1960). Conflict, arousal, and curiosity. New York: McGraw-Hill.

Chaiken, S. \& Stangor, C. (1987). Attitudes and attitude change. Annual Review of Psychology, 38, 575-630.

Clark, H. H. (1973). The language-as-a-fixed-effect fallacy: A critique of language statistics in psychological research. Journal of Verbal Learning and Verbal Behavior, $12,335-359$.

Eagly, A. H. \& Chaiken, S. (1993). The psychology of attitudes. Fort Worth, TX: Harcourt Brace Jovanovich.

Frijda, N. H. (1986). The emotions. Cambridge: Cambridge University Press.

Garner, R., Brown, R., Sanders, S. \& Menke, D. J. (1992). 'Seductive details' and learning from text. In K. A. Renninger, S. Hidi, \& A. Krapp (Eds.), The role of interest in learning and development (pp. 239-254). Hillsdale, NJ: Erlbaum.

Hidi, S. \& Anderson, V. (1992). Situational interest and its impact on reading and expository writing. In K. A. Renninger, S. Hidi, \& A. Krapp (Eds.), The role of interest in learning and development (pp. 215-238). Hillsdale, NJ: Erlbaum.

Hidi, S. \& Baird, W. (1988). Strategies for increasing text-based interest and students' recall of expository text. Reading Research Quarterly, 18, 277-294.

Hoey, M. (1983). On the surface of discourse. London: Allen \& Unwin.

Kieras, D. E. (1980). Initial mention as a signal to thematic content in technical passages. Memory \& Cognition, 8, 345-353.

Kieras, D. E. (1981). Topicalization effects in cued recall of technical prose. Memory \& Cognition, 9, 541-549. 
McGuire, W. J. (1972). Attitude change: The information-processing paradigm. In C. G. McClintock (Ed.), Experimental social psychology (pp. 108-141). New York: Holt, Rinehart \& Winston.

Reynolds, R. E. \& Shirey, L. L. (1988). The role of attention in studying and learning. In C. E. Weinstein, E. T. Goetz, \& P. A. Alexander (Eds.), Learning and study strategies (pp. 77-100). New York: Academic Press.

Rietveld, T. \& van Hout, R. (1993). Statistical techniques for the study of language and language behavior. Berlin: Mouton de Gruyter.

Rossiter, J. R. \& Percy, L. (1987). Advertising and promotion management. New York: McGraw-Hill.

Sax, G. (1980). Principles of educational and psychological measurement and evaluation. Belmont, CA: Wadsworth.

Wade, S. E. \& Adams, B. (1990). Effects of importance and interest on recall of biographical text. Journal of Reading Behavior, 22, 331-353.

Wade, S. E., Schraw, G., Buxton, W. M., \& Hayes, M. T. (1993). Seduction of the strategic reader: Effects of interest on strategies and recall. Reading Research Quarterly, 28, 93-114. 
Brought to you by | Radboud University Nijmegen (Radboud University Nijmegen) Authenticated | 172.16.1.226 